\title{
UTILIZAÇÃO DE Lactobacillus casei E CULTURA INICIADORA NA OBTENÇÃO DE IOGURTE SUPLEMENTADO COM INULINA E OLIGOFRUTOSE
}

\author{
RENATA HERNANDEZ BARROS FUCHS* \\ AILEY APARECIDA COELHO TANAMATI** \\ CARLISE MICHELS ANTONIOLI*** \\ ELAINE ANGÉLICA GASPARELLO*** \\ IVETE DONEDA***
}

\begin{abstract}
O objetivo deste trabalho foi elaborar iogurte desnatado simbiótico, utilizando cultura iniciadora (Lactobacillus bulgaricus e Streptococcus thermophilus), Lactobacillus casei como microrganismo probiótico e inulina e oligofrutose como ingredientes prebióticos. Testaram-se as características probióticas (resistência ao ácido e a bile) do Lactobacillus casei, avaliou-se a quantidade de bactérias láticas e as características físico-químicas ( $\mathrm{pH}$, acidez, composição química e viscosidade) do iogurte. Foram realizados testes de aceitação com o iogurte simbiótico adicionado de polpa e saborizante de morango, além de dois tipos de edulcorantes. O iogurte suplementado com prebióticos apresentou $\mathrm{pH} 4,33$ e acidez $1,15 \%$, bem como quantidade de bactérias láticas superior ao mínimo necessário para caracterizá-lo como probiótico. Lactobacillus casei mostrou-se resistente ao ácido e à bile, confirmando importantes características probióticas. O iogurte adicionado de prebióticos apresentou viscosidade maior que o não-suplementado. Não houve diferença significativa $(p<0,05)$ entre a aceitação dos iogurtes adoçados com os dois tipos de edulcorantes, sendo que ambos apresentaram índices de aceitação acima de $80 \%$.
\end{abstract}

PALAVRAS-CHAVE: IOGURTE; PREBIÓTICO; PROBIÓTICO; SIMBIÓTICO; INULINA; OLIGOFRUTOSE.

* Mestre em Biotecnologia, Docente do Departamento de Tecnologia em Alimentos, Universidade Tecnológica Federal do Paraná (UTFPR), Campus Campo Mourão (e-mail: piocoerenata@yahoo.com.br).

** Mestre em Química, Docente do Departamento de Tecnologia em Alimentos, UTFPR, Campus Campo Mourão (e-mail: aactanamati@cm.cefetpr.br).

*** Tecnólogas em Alimentos, UTFPR, Campus Campo Mourão (e-mail: rbarros@cm.cefetpr.br).

B.CEPPA, Curitiba, v. 24, n. 1, p. 83-98 jan./jun. 2006 


\section{INTRODUÇÃO}

O estado nutricional de populações de países desenvolvidos e em desenvolvimento vem sendo afetado por tendências desfavoráveis como o consumo excessivo de gorduras (principalmente saturadas), elevada ingestão de açúcares e diminuição considerável do consumo de amido, fibras alimentares, vitaminas e sais minerais. Essas tendências alimentares têm elevado a incidência de doenças crônico-degenerativas como, problemas cardiovasculares, câncer, hipertensão arterial, diabetes e obesidade. Dados da Organização Mundial de Saúde (OMS) mostram que essas doenças são responsáveis por 70 a $80 \%$ da mortalidade em países desenvolvidos e cerca de $40 \%$ em países em desenvolvimento (DE ANGELIS, 2002).

A preocupação dos consumidores em relação à alimentação vem mudando muito nas últimas décadas. $O$ alimento, anteriormente considerado apenas fonte de nutrientes essenciais à manutenção da vida, tornou-se objeto de estudos que o relacionam à prevenção de doenças e melhora da função de órgãos e tecidos. O conceito de alimentos funcionais e as descobertas de que alguns de seus componentes ativos são capazes de reduzir o risco de doenças ampliaram a dimensão da nutrição no século XXI (SALGADO, 2001). Dentre os alimentos funcionais destacam-se os probióticos, prebióticos e simbióticos. Os probióticos são microrganismos vivos que ingeridos em quantidade e freqüência determinados estabelecem o equilíbrio da microbiota intestinal. Os prebióticos são substâncias não-digeríveis pelo organismo humano que estimulam seletivamente a atividade de bactérias benéficas no cólon. Já os simbióticos são alimentos que agregam componentes probióticos e prebióticos (GIBSON e ROBERFROID, 1995; ROBERFROID, 1998).

A dieta pode desempenhar importante papel na manutenção e na melhoria da saúde humana, bem como na prevenção das doenças. Nesse contexto, a microbiota intestinal é considerada fator essencial que influi no bem-estar dos indivíduos. Acredita-se que em condições homeostáticas normais, a microbiota intestinal exerce papel central em numerosos aspectos benéficos. Pode-se categorizar seus componentes com base em seu papel potencialmente patogênico ou de promotor da saúde. O equilíbrio desses microrganismos é importante para a saúde do hospedeiro. Por razões óbvias existe considerável 
interesse em elevar o número e a atividade da microbiota do intestino grosso que promove a saúde (preferivelmente às custas das espécies mais danosas), aumentando o potencial da saúde in vivo. Como os alimentos proporcionam o principal combustível às bactérias intestinais, a forma de alcançar esse objetivo envolve o uso de suplementos dietéticos (GIBSON e ROBERFROID, 1995).

Existem duas estratégias dietéticas para aumentar os microrganismos benéficos para a microbiota intestinal. A primeira inclui o consumo de probióticos (sob forma de suplementos alimentares) contendo bactérias viáveis, que afetam beneficamente o hospedeiro pela melhoria do balanço da microbiota intestinal. Geralmente, são produtos lácteos fermentados ou não, contendo microrganismos probióticos viáveis (SCHREZENMEIR e VRESE, 2001). A segunda consiste em aumentar o número de microrganismos já residentes no trato intestinal pelo uso de prebióticos (substâncias alimentares não-digeríveis), que afetam beneficamente o hospedeiro pela estimulação seletiva do crescimento (ou da atividade) de número limitado de espécies bacterianas. Os prebióticos estimulam as bactérias endógenas específicas do hospedeiro no seu sítio de colonização (COLLINS e GIBSON, 1999).

Este trabalho teve como objetivo o desenvolvimento de iogurte desnatado simbiótico, utilizando-se inulina e oligofrutose como prebióticos, Lactobacillus caseicomo microrganismo probiótico e cultura iniciadora (Lactobacillus bulgaricus e Streptococcus thermophillus), bem como testar as características físico-químicas e probióticas (resistência ao ácido e à bile) do Lactobacillus casei.

\section{MATERIAL E MÉTODOS}

O experimento foi realizado nos laboratórios de Tecnologia em Alimentos do Centro Federal de Educação Tecnológica do Paraná (CEFET), unidade de Campo Mourão.

\subsection{MICRORGANISMOS}

\subsubsection{Cultura Iniciadora}

Utilizou-se fermento lácteo Rich® (Christian Hansen), constituído de 
cultura super concentrada de Lactobacillus bulgaricus e Streptococcus thermophillus na proporção 1:1.

\subsubsection{Lactobacillus casei}

Foram utilizadas cepas de Lactobacillus casei isoladas de leite fermentado ("Yakult").

\subsection{PREBIÓTICOS}

Para suplementação do iogurte foram empregados inulina (Raftiline HP, Orafti) e oligofrutose (Raftilose P95, Orafti), cedidos pela empresa Nutrinova.

\subsection{EDULCORANTES}

Para conferir doçura ao iogurte foram usados o adoçante dietético líquido "Zero cal" (Aspartame) e o Multi-adoçante Stevia Plus Lowçucar em pó, composto por ciclamato de sódio, sacarina sódica e steviosídeo.

\subsection{SABORIZANTES}

O iogurte simbiótico foi adicionado de saborizante de morango (SelectaDuas Rodas Industrial), composto por sacarose e amido modificado, além de morango em calda (Marca Lar) previamente escorrido e processado em liquidificador.

\subsection{METODOLOGIA}

\subsubsection{Isolamento do Lactobacillus casei}

Foram isoladas cepas de Lactobacillus caseia partir de leite fermentado (“Yakult") em meio MRS ágar (MAN, ROGOSA e SHARPE, 1961) pela técnica de semeadura em profundidade (ZAYED e WINTER, 1995). As placas permaneceram em estufa bacteriológica na temperatura de $37^{\circ} \mathrm{C}$ por 48 horas.

\subsubsection{Ativação das cepas}

As colônias obtidas foram ativadas mediante três repiques sucessivos 
em leite em pó desnatado e reconstituído a 10\% (m/v). Após cada repique os tubos com leite permaneceram em estufa na temperatura de $37^{\circ} \mathrm{C}$ por 24 horas (BALDUÍNO, OLIVEIRA e HAULY, 1999).

\subsubsection{Preparo do iogurte}

O substrato para fermentação foi constituído por leite em pó desnatado reconstituído a 10\% (m/v), 5\% (m/v) de oligofrutose e 1\% $(\mathrm{m} / \mathrm{v})$ de inulina. Submeteu-se o substrato a tratamento térmico em autoclave, sob vapor fluente, durante 45 minutos.

Resfriou-se o substrato para temperatura de $42^{\circ} \mathrm{C}$, adicionou-se $0,05 \%$ $(\mathrm{m} / \mathrm{v})$ de cultura iniciadora e $10 \%(\mathrm{v} / \mathrm{v})$ das cepas de Lactobacillus casei já ativadas (8 log UFC. $\mathrm{mL}^{-1}$ ).

Homogeneizou-se o preparado, cuidadosamente, o qual foi levado à estufa bacteriológica $\left(42^{\circ} \mathrm{C}\right)$ até a coagulação do leite (aproximadamente 6 horas).

\subsubsection{Determinação do pH}

Determinou-se o pH do iogurte em potenciômetro digital, previamente calibrado (IAL, 1985).

\subsubsection{Determinação de acidez}

A acidez do iogurte foi determinada por titulação, utilizando-se solução de $\mathrm{NaOH} 0,1 \mathrm{~N}$ conforme técnica $n^{\circ} 970.124$ da AOAC (1995), expressa em porcentagem de ácido lático.

\subsubsection{Adição de Edulcorantes}

Adicionou-se ao iogurte suplementado $0,5 \%(\mathrm{v} / \mathrm{v})$ de "Zero cal" (aspartame) em uma das amostras e $0,8 \%(\mathrm{~m} / \mathrm{v})$ de Multiadoçante (ciclamato de sódio, sacarina sódica e steviosídeo) em outra amostra, as quais foram submetidas ao teste de aceitação. As concentrações de edulcorantes adicionadas aos iogurtes foram determinadas em testes preliminares. 


\subsubsection{Adição de sabor}

A formulação do iogurte adoçado com multiadoçante foi composta por $5 \%(\mathrm{~m} / \mathrm{v})$ de polpa de morango, $0,3 \%(\mathrm{~m} / \mathrm{v})$ de saborizante de morango, $1 \%(\mathrm{~m} / \mathrm{v})$ de inulina, $5 \%(\mathrm{~m} / \mathrm{v})$ de oligofrutose, $87,9 \%(\mathrm{~m} / \mathrm{v})$ de leite em pó desnatado e $0,8 \%(\mathrm{~m} / \mathrm{v})$ de multiadoçante. O produto adoçado com aspartame continha a mesma quantidade de polpa, saborizante e prebióticos, além de $0,5 \%(\mathrm{v} / \mathrm{v})$ de aspartame e $88,2 \%(\mathrm{~m} / \mathrm{v})$ de leite em pó desnatado.

\subsubsection{Avaliação das características probióticas}

\subsubsection{Resistência ao ácido}

Testou-se a resistência do microrganismo (Lactobacillus casei) ao ácido de acordo com a metodologia sugerida por CLARK et al., (1993) apud RÖNKÄ et al., (2003). Algumas modificações foram feitas com relação à ativação dos microrganismos e intervalos de avaliação da viabilidade celular. A resistência do microrganismo ao ambiente ácido foi avaliada expondo-o ao caldo MRS com baixos valores de $\mathrm{pH}(\mathrm{pH}$ 2,0 , e pH 4,0) durante 3 horas. Esse período retrata o tempo médio de permanência de um alimento no estômago, órgão em que o microrganismo é exposto à acidez (MAHAN e ESCOTT-STUMP, 2002).

Para ativação do microrganismo foram realizados três repiques sucessivos de Lactobacillus casei $(10 \% \mathrm{v} / \mathrm{v})$ em leite em pó desnatado reconstituído a $10 \%(\mathrm{~m} / \mathrm{v})$, seguidos de três repiques sucessivos em caldo MRS ( $\mathrm{pH} \mathrm{6,1-6,2),} \mathrm{sendo} \mathrm{que} \mathrm{a} \mathrm{cada} \mathrm{repique} \mathrm{as} \mathrm{cepas}$ permaneceram em estufa bacteriológica ( $37^{\circ} \mathrm{C} / 24$ horas). Transferiuse o microrganismo ativo para meio controle caldo MRS $(\mathrm{pH} 6,1-6,2)$, caldo MRS ( $\mathrm{pH} \mathrm{4,0)} \mathrm{e} \mathrm{caldo} \mathrm{MRS} \mathrm{(} \mathrm{pH} 2,0)$. Os tubos permaneceram em estufa bacteriológica $\left(37^{\circ} \mathrm{C}\right)$ por três horas, avaliando-se a viabilidade celular após 0, 1,5 e 3,0 horas da adição do inóculo.

\subsubsection{Resistência à bile}

A resistência do microrganismo (Lactobacillus casel) à bile foi testada segundo metodologia sugerida por GILLILAND et al. (1984) apud RÖNKÄ et al., (2003), alterada em relação à ativação do microrganismo

e intervalo de avaliação da viabilidade celular. Testou-se a resistência 
do microrganismo em caldo MRS ( $\mathrm{pH} 6,1-6,2)$ com $0,3 \%$ de bile bovina e sem a presença de bile bovina (controle) num período total de três horas ( $0,1,5$ e 3 horas).

Para ativação do microrganismo foram realizados três repiques sucessivos de Lactobacillus casei $(10 \% \mathrm{v} / \mathrm{v})$ em leite em pó desnatado reconstituído a $10 \%(\mathrm{~m} / \mathrm{v})$, seguido de três repiques sucessivos em caldo MRS ( $\mathrm{pH} \mathrm{6,1-6,2).} \mathrm{Transferiu-se} \mathrm{o} \mathrm{microrganismo} \mathrm{ativo} \mathrm{para} \mathrm{meio}$ controle (sem adição de bile bovina) e com adição de $0,3 \%(\mathrm{~m} / \mathrm{v})$ de bile bovina. Os tubos permaneceram em estufa bacteriológica $\left(37^{\circ} \mathrm{C}\right)$ por três horas, avaliando-se a viabilidade celular após $0,1,5$ e 3,0 horas da adição de inóculo. As análises foram realizadas em triplicata.

\subsubsection{Avaliação da viabilidade celular}

Determinou-se a viabilidade celular pela técnica de semeadura em profundidade (ZAYED e WINTER, 1995), utilizando o meio ágar MRS. As placas foram incubadas a $37^{\circ} \mathrm{C}$ por 48 horas, as colônias contadas e os resultados expressos em log UFC. $\mathrm{mL}^{-1}$.

\subsubsection{Avaliação da estabilidade química e microbiológica durante o armazenamento}

As amostras de iogurte com e sem suplementação de prebióticos foram submetidas à avaliação do número de bactérias lácticas presentes nos produtos após $0,7,14,21$ e 28 dias da sua fermentação.

Depois da fermentação, as amostras foram acondicionadas em geladeira, a $4^{\circ} \mathrm{C}$, até os respectivos dias para a avaliação da viabilidade celular. A cada dia de avaliação mediu-se o valor do $\mathrm{pH}$ e a acidez das duas formulações de iogurte (com e sem suplementação de prebióticos). No $28^{\circ}$ dia de armazenamento realizaram-se as análises microbiológicas de coliformes totais, coliformes fecais, bolores e leveduras, conforme a RDC 12 da ANVISA (2001).

\subsubsection{Análise da viscosidade}

As amostras de $250 \mathrm{~mL}$ dos iogurtes com e sem suplementação foram preparadas e armazenadas sob refrigeração $\left(4^{\circ} \mathrm{C}\right)$ durante 24 horas. Analisou-se a viscosidade, em Viscosímetro Brookfield modelo RVT, utilizando spindle 6 e velocidade de $5 \mathrm{rpm}$. Os resultados foram 
expressos em centipoise $(\mathrm{cP})$.

\subsubsection{Avaliação da composição química}

O produto foi submetido às determinações de umidade, cinzas, carboidratos, proteínas e lipídios, segundo as Normas Analíticas do Instituto Adolfo Lutz (IAL, 1985).

\subsubsection{Avaliação sensorial}

Polpa de morango e saborizante foram incorporadas ao iogurte simbiótico, testando-se o efeito da adição de dois edulcorantes na aceitação global do produto.

Aplicou-se o teste de aceitação, utilizando escala hedônica estruturada de nove pontos ( 1 = desgostei muitíssimo; 9 = gostei muitíssimo) para avaliar a aceitabilidade geral dos iogurtes e calculou-se o índice de aceitação dos produtos (DUTCOSKY, 1996). Avaliou-se o índice de aceitação pela análise de variância (ANOVA) para verificar a existência de diferença significativa $(p<0,05)$ entre as amostras (GACULA e SINGH, 1984).

Realizou-se a avaliação sensorial com equipe formada por 50 julgadores não-treinados. Amostras de $100 \mathrm{~mL}$ das duas formulações de iogurte foram oferecidas aos julgadores em copos plásticos brancos descartáveis, codificados com número de três dígitos ao acaso, acompanhadas de copo de água mineral em temperatura ambiente (para ser ingerida entre as amostras). As amostras foram oferecidas separadamente e em ordem aleatorizada aos julgadores (MEILGAARD, CIVILLE e CARR, 1987). Na ficha utilizada no teste havia espaço destinado para comentários sobre os produtos.

\section{RESULTADOS E DISCUSSÃO}

\subsection{RESISTÊNCIA AO ÁCIDO}

Observou-se (Tabela 1) que o meio com $\mathrm{pH} 2,0$ promoveu queda no número de células viáveis presentes, o qual permaneceu constante no meio com $\mathrm{pH} 4,0$. No entanto, o menor valor encontrado na terceira hora de avaliação $\left(9,09 \log\right.$ UFC. $\left.\mathrm{mL}^{-1}\right)$ não se distanciou muito do valor 
$\left(9,34 \log\right.$ UFC $\left.\cdot \mathrm{mL}^{-1}\right)$ verificado no meio controle $(\mathrm{pH} 6,1-6,2)$.

TABELA 1 - AVALIAÇÃO DA VIABILIDADE CELULAR DO Lactobacillus casei DURANTE A EXPOSIÇÃO AO CALDO MRS COM DIFERENTES VALORES DE PH (TESTE DE RESISTÊNCIA AO ÁCIDO)

\begin{tabular}{cccc}
\hline & \multicolumn{3}{c}{ Viabilidade celular $\left(\log\right.$ UFC. $\left.\mathrm{mL}^{-1}\right)$} \\
\hline Meios Testados & Hora $(0)$ & Hora $(1,5)$ & Hora $(3,0)$ \\
\hline MRS pH 6,1-6,2 & 9,48 & 9,47 & 9,34 \\
MRS pH 4,0 & 9,48 & 9,35 & 9,35 \\
MRS pH 2,0 & 9,48 & 9,38 & 9,09 \\
\hline
\end{tabular}

O Lactobacillus casei demonstrou resistência ao ambiente ácido testado, evidenciando uma importante característica probiótica. Desta forma, o microrganismo é capaz de ultrapassar a primeira barreira fisiológica do organismo que é o baixo valor de $\mathrm{pH}$ encontrado no estômago (GIBSON, 2004).

\subsection{RESISTÊNCIA À BILE}

A presença de bile bovina não alterou a viabilidade celular do microrganismo (Tabela 2), que se manteve estável até a terceira hora de avaliação. Tal fato comprova que o Lactobacillus casei é resistente à bile, sendo capaz de ultrapassar essa barreira fisiológica do organismo humano para atingir o intestino e potencialmente colonizá-lo (GIBSON, 2004).

TABELA 2 - AVALIAÇÃO DA VIABILIDADE CELULAR DO Lactobacillus casei DURANTE TRÊS HORAS DE EXPOSIÇÃO AO CALDO MRS COM ADIÇÃO DE BILE (TESTE DE RESISTÊNCIA À BILE)

\begin{tabular}{cccc}
\hline \multicolumn{4}{c}{ Viabilidade celular $\left(\log\right.$ UFC. $\left.\mathrm{mL}^{-1}\right)$} \\
\hline Meios Testados & Hora $(0)$ & Hora $(1,5)$ & Hora $(3,0)$ \\
\cline { 2 - 4 } MRS sem adição bile bovina & $>9,48$ & $>9,48$ & $>9,48$ \\
MRS com 0,3\% de bile bovina & $>9,48$ & $>9,48$ & $>9,48$ \\
\hline
\end{tabular}

\subsection{TESTE DE ESTABILIDADE QUÍMICA E MICROBIOLÓGICA}

$\mathrm{Na}$ Tabela 3 pode-se observar a evolução dos valores de $\mathrm{pH}$, acidez e 
viabilidade celular dos iogurtes com e sem suplementação de prebióticos. Com o passar dos dias de armazenamento, o pH das duas formulações de iogurte decresceu e a acidez aumentou. Tal fato ocorreu devido ao metabolismo das bactérias que degradam o substrato presente no meio (lactose), obtendo-se como produto final, principalmente, ácido láctico (FERREIRA, 2002).

TABELA 3 - VALORES DE pH, ACIDEZ E VIABILIDADE CELULAR DO IOGURTE DESNATADO SEM E COM SUPLEMENTAÇÃO DE PREBIÓTICOS DURANTE 28 DIAS DE ARMAZENAMENTO

\begin{tabular}{c|c|c|c}
\hline \multicolumn{5}{c}{$\begin{array}{c}\text { Iogurte sem suplementação } \\
\text { Parâmetros Avaliados }\end{array}$} \\
\hline Dia & $\mathrm{pH}$ & $\begin{array}{c}(\%) \text { de Ácido } \\
\text { Lático }\end{array}$ & $\begin{array}{c}\text { Viabilidade celular } \\
(\text { Iog UFC.m L }\end{array}$ \\
\hline 0 & 4,33 & 1,27 & 8,51 \\
\hline 7 & 4,26 & 1,41 & 8,85 \\
\hline 14 & 4,13 & 1,65 & 8,89 \\
\hline 21 & 4,10 & 1,78 & 8,57 \\
\hline 28 & 4,19 & 1,78 & 8,99 \\
\hline \multicolumn{5}{|c|}{ logurte com suplementação } \\
Parâmetros Avaliad os \\
\hline Dia & $\mathrm{pH}$ & $\begin{array}{c}\text { (\%) de Ácido } \\
\text { Lático }\end{array}$ & $\begin{array}{c}\text { Viabilidade celular } \\
\text { (log UFC.m L }\end{array}$ \\
\hline 0 & 4,33 & 1,15 & 8,96 \\
\hline 7 & 4,21 & 1,46 & 9,32 \\
\hline 14 & 4,26 & 1,56 & 8,29 \\
\hline 21 & 4,20 & 1,61 & 9,13 \\
\hline 28 & 4,20 & 1,76 & 8,69 \\
\hline
\end{tabular}

Apesar de vários autores (COLLINS e GIBSON, 1999; GIBSON et al., 1995 e GIBSON, 2004) evidenciarem que a adição de prebióticos preserva a viabilidade de bactérias láticas durante a vida-de-prateleira do produto, tal condição não foi verificada neste trabalho. Ambas as formulações (suplementada ou não com prebióticos) apresentaram contagem de bactérias láticas semelhante durante todo o período avaliado (Tabela 3). Isto pode ter ocorrido em razão do meio utilizado para fermentação do probiótico (leite em pó reconstituído) ser rico em lactose, substrato preferencial das bactérias ácido-lácticas, que deve ter exercido o mesmo efeito protetor que a inulina e oligofrutose (FUCHS et al., 2005). 
Mesmo no último dia de avaliação, a quantidade de bactérias láticas presentes em ambas as formulações foi superior ao mínimo para caracterizar os iogurtes como probióticos (7 log UFC. $\left.\mathrm{mL}^{-1}\right)$.

As análises microbiológicas, realizadas no iogurte simbiótico no $28^{\circ}$ dia de armazenamento, evidenciaram ausência de coliformes totais, coliformes fecais, bolores e leveduras.

\subsection{VISCOSIDADE}

O iogurte sem suplementação apresentou viscosidade média de $13.500 \mathrm{cP}$, enquanto o iogurte suplementado alcançou média de $16.000 \mathrm{cP}$.

O iogurte suplementado apresentou maior viscosidade devido ao aumento de sólidos totais provocado pela adição de oligofrutose e inulina, que também auxiliam na formação de gel. Tratando-se de substância altamente higroscópica, a inulina pode ligar-se à água e formar rede semelhante ao gel alterando as propriedades reológicas do sistema (GEL-NAGAR et al., 2002). Tal condição é favorável, já que a retirada de gordura do leite promove a formação de iogurte com baixa viscosidade (TAMIME e ROBINSON, 1991). Tendo cadeia maior, a inulina é menos solúvel que a oligofrutose e apresenta habilidade de formar microcristais de inulina quando misturada em água ou leite. Esses microcristais não são percebidos na boca, mas interagem para formar textura finamente cremosa que promove sensação semelhante à da gordura. Por esse motivo, a inulina tem sido usada com sucesso na substituição de gordura em vários produtos alimentares como bolos, chocolates, embutidos e produtos lácteos (NINESS, 1999).

GEL-NAGAR et al. (2002) observaram que o acréscimo de inulina em sorvete de iogurte com baixo teor de gorduras aumentou significativamente sua viscosidade, devido às interações da fibra solúvel com a parte aquosa do produto.

A funcionalidade da inulina está baseada em seu efeito sobre soluções aquosas em vários níveis de sólidos e quanto maior a concentração de inulina, maior a viscosidade (GEL - NAGAR et al., 2002). 


\subsection{COMPOSIÇÃO QUÍMICA}

O teor de umidade do iogurte $(86,10 \%)$ está de acordo com os valores encontrados em bebidas lácteas fluídas, variando de $87-91 \%$ segundo CECCHI (1999).

O iogurte apresentou teor de cinzas de $0,03 \%$, sendo que os minerais encontrados em maior quantidade em produtos lácteos são cálcio, fósforo e potássio (TAMIME e ROBINSON, 1991). De acordo com COUDRAY et al. (2003), a mistura de frutooligossacarídios melhora a absorção intestinal do cálcio e o balanço desse mineral em ratos.

Os teores de proteínas $(3,10 \%)$ e lipídios $(0,00 \%)$ determinados no iogurte simbiótico enquadraram-se no padrão dos iogurtes usados para comparação, porém o teor de carboidratos $(10,78 \%)$ mostrou-se maior que 0 dos iogurtes desnatados encontrados no mercado (PHILIPPI, SZARFARC e LATTERZA, 1996). Tal fato deve-se à adição dos prebióticos (inulina e oligofrutose) na formulação do produto desenvolvido, já que o único carboidrato presente em iogurtes naturais é a lactose (tradicionalmente encontrada no leite). Como os prebióticos (inulina e oligofrutose) não são digeríveis, praticamente, não influenciam o valor calórico do iogurte (BOT et al., 2004), acreditando-se que esse valor seja semelhante ao dos iogurtes utilizados para comparação.

\subsection{AVALIAÇÃO SENSORIAL}

A análise de variância dos resultados do teste de aceitação não indicou diferença significativa $(p<0,05)$ entre as amostras adicionadas com os dois tipos de edulcorantes. A amostra A (multiadoçante) obteve índice de aceitação de $82,5 \%$ e a amostra B (aspartame) índice de $86 \%$.

Os julgadores que comentaram o grau de doçura e coloração dos iogurtes avaliados consideraram que as amostras poderiam ser mais doces (18\%), apresentar coloração rosa mais intensa (10\%) e sabor de morango mais intenso (6\%).

Os resultados do teste de aceitação podem ser observados nas Figuras 1 e 2. 
FIGURA 1 - PORCENTAGEM DE ACEITAÇÃO DO IOGURTE DESNATADO SIMBIÓTICO ADOÇADO COM MULTIADOCANTE

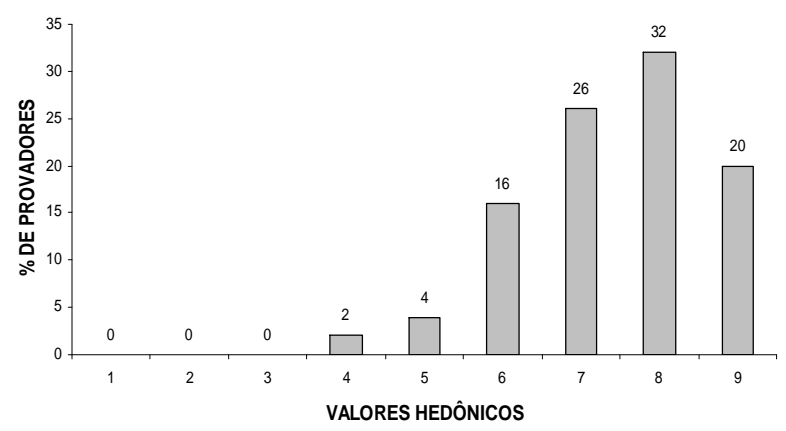

FIGURA 2 - PORCENTAGEM DE ACEITAÇÃO DO IOGURTE DESNATADO SIMBIÓTICO ADOÇADO COM ASPARTAME

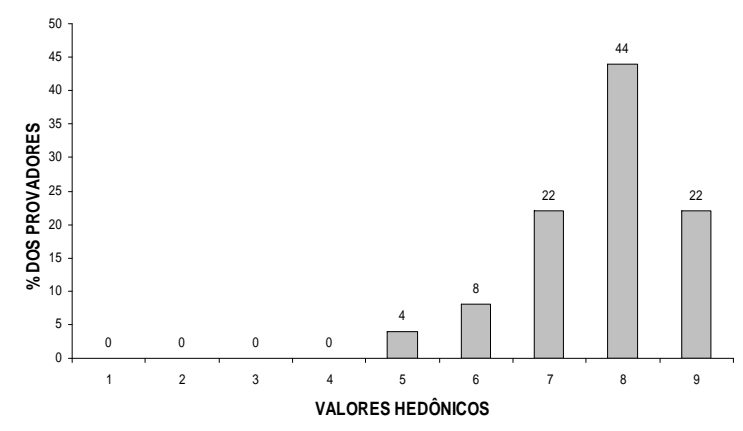

\section{CONCLUSÃO}

Obteve-se iogurte desnatado com características simbióticas, utilizando inulina e oligofrutose (probióticos), Lactobacillus casei (probiótico) e cultura iniciadora composta por Lactobacillus bulgaricus e Streptococcus thermophillus. 
O microrganismo Lactobacillus casei evidenciou resistência ao ácido e à bile, confirmando importantes características probióticas.

O iogurte apresentou quantidade de bactérias láticas superior ao mínimo necessário para caracterizar o produto como probiótico, além de viscosidade adequada e ótimo índice de aceitação.

\begin{abstract}
UTILIZATION OF Lactobacillus casei AND STARTER CULTURE IN ELABORATION OF YOGHURT SUPPLEMENTED WITH INULIN AND OLIGOFRUCTOSE

The aim of this work was to elaborate a skimmed symbiotic yoghurt, using starter culture (Lactobacillus bulgaricus and Streptococcus thermophillus), Lactobacillus casei as probiotic microorganism and inulin and oligofructose as prebiotic ingredients. The probiotics characteristics (acid and bile resistance) of $L$. casei and the number of lactic acid bacterias in the product had been tested, as well as the physicochemical characteristics of the yoghurt $(\mathrm{pH}$, acidity, chemical composition and viscosity). Acceptance tests had been carried out with the symbiotic yoghurt added with strawberry pulp and flavour, and two different types of sweetening agents. The yoghurt supplemented with prebiotics presented $\mathrm{pH} 4.33$, acidity of $1.15 \%$ and amount of lactic acid bacteria superior to the minimum necessary to characterize it as probiotic. L. casei showed resistance to acid and bile, confirming important probiotics characteristics. The prebiotic yoghurt presented higher viscosity than the not supplemented one. There was no significant difference between the acceptance (above $80 \%$ ) of yoghurts sweetened with the two types of sweetening agents.
\end{abstract}

KEY-WORDS: YOGHURT; PREBIOTIC; PROBIOTIC; SYMBIOTIC; INULIN; OLIGOFRUCTOSE.

\title{
REFERÊNCIAS
}

1 ANVISA. Agência Nacional de Vigilância Sanitária. Resolução RDC n.12 - 02 de janeiro de 2001. Disponível em http:||www.anvisa.org.br/legis/ Acesso em: 15/07/04.

2 AOAC. Association of Official Analytical Chemist. Official Methods of Analysis of AOAC International. $15^{\text {th }}$ ed. Washington, D.C., 1995.

3 BALDUINO, R.; OLIVEIRA, A. S.; HAULY, M. C. O. Influência da fonte de carbono e da temperatura sobre a fermentação lática desenvolvida por cultura mista de bactérias láticas. Ciência e Tecnologia de Alimentos, v.19, n.3, p.363-366, 1999.

4 BOT, A.; ERLE. U.; VREEKER, R.; AGTEROF, W.G.M.; Influence of crystallization conditions on the large deformation rheology of inulin gels. Food hydrocolloyds, v. 18, n. 4, p.547-556, 2004. 
$5 \mathrm{CECCHI}, \mathrm{H}$. M. Fundamentos teóricos e práticos em análises de alimentos. 2 ed. Campinas: Unicamp, 2005. 208 p.

6 COLLINS, M. D; GIBSON, G. R. Probiotics, prebiotics and synbiotics: approaches for modulating the microbial ecology of the gut. American Journal of Clinical Nutrition, v.69. p.10525-10575, 1999.

7 COUDRAY, C.; TRESSOL, J.C.; GUEUX, E.; RAYSSIGUIER, Y. Effects of inulin-type fructans of different chain length and type of branching or intestinal absorption and balance of calcium and magnesium in rats. European Journal of Nutrition, v. 42; n. 2, p. 91-98, 2003.

8 DE ANGELIS, R. C. Alimentos de origem vegetal são saudáveis: verdades e alguns questionamentos. Nutrição em Pauta, v. 57. p. 30-34, 2002.

9 DUTCOSKY, S. D. Análise sensorial de alimentos. Curitiba: Champagnat. 1996, $123 \mathrm{p}$.

10 FERREIRA, C. L. L. F. Acidez em leite e produtos lácteos: Aspectos fundamentais. Viçosa: UFV, 2002. 26 p.

11 FUCHS, R. H. B.; BORSATO, B.; BONA, E.; HAULY, M.C.O. "logurte" de soja suplementado com oligofrutose e inulina. Ciência e Tecnologia de Alimentos, v. 25, n. 1, p. 175-181, 2005.

12 GACULA, J. R.; SINGH, J. Statistical methods in food and consumer research. Orlando: Academic Press, 1984. 505 p.

13 GEL-NAGAR; CLOWES, G; TUDORICÃ, C. M.; KURI, V. Rheological quality and stability of yog-ice cream with added inulin. International Journal of Dairy Technology, v. 55; n. 2, p. 89-93, 2002.

14 GIBSON, G. R.; BEATTY, E. R.; WANG, X.; CUMMINGS, J. H. Selective stimulation of bifidobacteria in the human colon by oligofructose and inulin. Gastroenterology, v. 108. p. 975-982, 1995.

15 GIBSON, G. R.; ROBERFROID, M. B. Dietary modulation of the human colonic microbiota - introducing the concept of prebiotics. Journal of Nutrition, v. 125. p.1401-1412, 1995.

16 GIBSON, G. R. Fibre and effects on probiotics (the probiotic concept). Clinical Nutrition Supplements, v.1. p. 25-31, 2004.

17 IAL. Instituto Adolfo Lutz. Normas analíticas do Instituto Adolfo Lutz: métodos químicos e físicos para análise de alimentos. 3 ed. São Paulo, 1985. v. 1

18 MAHAN, K. L.; ESCOTT-STUMP, S. Krause: alimentos, nutrição \& dietoterapia. 10 ed. São Paulo: Roca, 2002. 
19 MAN, J. C.; ROGOSA, M.; SHARPE, M. E. A medium for the cultivation of Lactobacilli. Journal of Bacteriology, v.23. p.130-135, 1961.

20 MEILGAARD, M.; CIVILLE, G. V.; CARR, B. T. Sensory evaluation techniques. Boca Raton: CRC, 1987. v. 2.

21 NINESS, K. R. Inulin and oligofructose: what are they? Journal of Nutrition, v. 129 (Suppl.), p.1402-1406, 1999.

22 PELEGRINE, D. H.; VIDAL, J. R. M. B.; GASPARETTO, C. A. Estudo da viscosidade aparente das polpas de manga (Keitt) e abacaxi (Pérola). Ciência e Tecnologia de Alimentos., v.20, n.1, p.128-131, 2000

23 PHILIPPI, S.T.; SZARFARC, S.C.; LATTERZA, A. R. Virtual Nutri [software]. São Paulo: Departamento de Nutrição/ Faculdade de Saúde Publica/USP, 1996. (versão 1.0 for Windows).

24 ROBERFROID, M. B. Prebiotics and synbiotics: concepts and nutricional properties. British Journal of Nutrition, v. 80 (suppl.), p. S197-S202, 1998.

25 RÖNKÄ, E.; MALINEN, E.; SAARELA, M.; RINTA-KOSKI, M.; AARNIKAUNNAS, J.; PALVA, A. Probiotic and milk technological properties of Lactobacillus brevis. International Journal of Food Microbiology, v.83. p.63-74, 2003.

26 SALGADO, J. M. Impacto dos alimentos funcionais para a saúde. Nutrição em Pauta, v. 48. p.10-17, 2001.

27 SCHREZENMEIR, J.; VRESE, M. Probiotics, prebiotics and synbiotics approaching a definition. American Journal of Clinical Nutrition, v.73. p. 3615-3645, 2001.

28 TAMIME, A. Y.; ROBINSON, A. YOGUR: ciência y tecnología. Zaragoza (España): Acribia, 1991. p. 279.

29 ZAYED G.; WINTER J. Batch and continuous production of lactic acid from salt whey using free and immobilized cultures of lactobacilli. Applied Microbrobiology Biotechnology, v. 44. p.362-366, 1995. 